\title{
Osteoporosis and People with Down Syndrome: A Preliminary Descriptive Examination of the Intellectual Disability Supplement to the Irish Longitudinal Study on Ageing Wave 1 Results
}

\author{
Éilish A. Burke ${ }^{*}$, Rachael Carroll1, Máire 0’Dwyer ${ }^{2}$, J. Bernard Walsh ${ }^{3}$, Philip McCallion ${ }^{4}$, \\ Mary McCarron 5 \\ ${ }^{1}$ School of Nursing and Midwifery, Trinity College Dublin, Dublin, Ireland \\ ${ }^{2}$ School of Pharmacy and Pharmaceutical Sciences, Trinity College Dublin, Dublin, Ireland \\ ${ }^{3}$ Department of Medical Gerontology, Trinity College Dublin, Dublin, Ireland \\ ${ }^{4}$ College of Public Health, Temple University, Philadelphia, PA, USA \\ ${ }^{5}$ Faculty of Health Sciences, Trinity College Dublin, Dublin, Ireland \\ Email: *eburke7@tcd.ie
}

How to cite this paper: Burke, É.A., Carroll, R., O’Dwyer, M., Walsh, J.B., McCallion, P. and McCarron, M. (2018) Osteoporosis and People with Down Syndrome: A Preliminary Descriptive Examination of the Intellectual Disability Supplement to the Irish Longitudinal Study on Ageing Wave 1 Results. Health, 10, 1233-1249. https://doi.org/10.4236/health.2018.109095

Received: July 26, 2018

Accepted: September 23, 2018

Published: September 26, 2018

Copyright $\odot 2018$ by authors and Scientific Research Publishing Inc. This work is licensed under the Creative Commons Attribution International License (CC BY 4.0).

http://creativecommons.org/licenses/by/4.0/

\begin{abstract}
Background: People with Down syndrome (DS) are a high "at risk" group to develop osteoporosis. Increased morbidity associated with older age, higher prevalence of Alzheimer dementia, hypotonia, hypogonadism, and thyroid disease, are all features of DS and predispose this cohort to musculoskeletal complications. Methods: The Intellectual Disability Supplement to The Irish Longitudinal Study on Ageing (IDS-TILDA) is a representative study of the aging of adults with intellectual disability in Ireland. The sample $(\mathrm{N}=753)$ included 147 people with DS. Data was gathered on participants' health status, behavioural health, health screenings and activities of daily living. The prevalence of osteoporosis and related risk factors among people with DS was specifically examined. Findings: Of the 147 participants with DS, 9.4\% reported a doctor's diagnosis of osteoporosis; a much lower figure than prevalence of risk factors would suggest. Predisposing factors identified included higher than general population rates of thyroid disease (37.4\%), epilepsy $(19.3 \%)$, sedentary lifestyle $(51.7 \%)$ and the majority of the females reporting having experienced menopause (61\%). Bone health screening was low at $(8 \%)$ despite the presence of such high levels of risk factors in this population. Conclusion: Given the risk factor findings and the hidden nature of osteoporosis, underreported incidence among people with Down syndrome seems probable. Further investigations and systematic screening are required.
\end{abstract}




\section{Keywords}

Intellectual Disability, Down Syndrome, Osteoporosis, Bone Health, Bone Fragility Risk

\section{Introduction}

Osteoporosis and osteopenia are chronic skeletal conditions characterized by low bone density and microarchitectural deterioration of bone tissue [1] [2] [3]. With ageing, enhanced resorption and decreased bone formation occurs leading to a net loss of bone mass and ultimately risk of osteoporosis and osteopenia [4]. The World Health Organization (WHO), the International Osteoporosis Foundation (IOF) and bone health research literature, identify a number of non-modifiable and modifiable risk factors associated with the development of osteoporosis and osteopenia. Non-modifiable risks include female gender, increased age, family history of osteoporosis, and being Caucasian. Late menarche, early menopause and low endogenous estrogen levels are also associated with low bone mineral density [1] [2] [5] [6]. Modifiable risks include sedentary lifestyle, smoking, poor dietary habits, lack of sunlight and estrogen deficiency. Certain medications are also indicated as risk factors for example anticonvulsants and glucocorticoids [7]. Higher prevalence of risk factors has been shown to lead to both a higher potential of fractures and higher rates of morbidity with devastating consequences for independence, quality of life and overall health and well-being [5] [8].

Osteoporosis and osteopenia have been widely investigated in the general population [5] [9] [10], however relatively under investigated among people with intellectual disability (ID), and especially among people with Down syndrome (DS) [11]-[16].

\section{Down Syndrome \& Osteoporosis}

Down syndrome (DS) is one of the most commonly known genetic causes of ID and its pathogenesis are well documented [17]. Increased life expectancy is unmistakable among people with DS [18] prompting an increased risk to older age health conditions such as osteoporosis. People with DS are specifically vulnerable to musculoskeletal disorders and are more likely to have infrequent health checks or routine screening [19].

Prevalent features among people with DS contributing to osteoporosis include low estrogen levels, late menarche and early menopause in females as well as hypogonadism in males [20] [21]. Increased ageing and early onset of ageing related decline add further burden [22] [23] [24]. Thyroid dysfunction is commonly identified among people with DS, with hypothyroidism the most common presentation [25] [26] impacting significantly on skeletal health and later life osteoporosis [27] [28]. As people with DS age the prevalence of Alzheimer 
dementia and associated epilepsy increases [29]. Alzheimer's disease and epilepsy do not directly affect bone status but the subsequent anticonvulsant medications (AEDs) contribute to disruption of bone formation and remodeling especially second generation anticonvulsants [7]. Increased risk of falls, both as a consequence of and a contributor to reduced bone health are also associated with Alzheimer's disease and epilepsy. However, Torr, Strydom [30], in their review warn that decline in adults with DS should not be assumed to be associated with Alzheimer's dementia as functional decline may be as a consequences of a number of underlying conditions especially sensory and musculoskeletal impairment.

Physical activity benefits bone mass, stability, balance and contributes to improved quality of life [31] [32] however physical activity levels at rate to accrue health benefit is low among those with DS [33]. Further, the prevalence of overweight and obesity has been noted at higher levels among people with DS than the general population [34] [35]. Obesity has a cumulative effect on bone health due to the retention of vitamin $\mathrm{D}$ by the increased adipose tissue, therefore making it less available for bone metabolism [36] as well as the extra loading on bones and joints increasing the likelihood of falls and possible fracture [37]. Obesity may also be a reflection of imbalanced or poor dietary habits. Known secondary causes of low bone mineral density include poor nutrition and gastrointestinal conditions such as coeliac disease, gastro-reflux disease, and chronic constipation, all highly prevalent among adults with ID and DS [38] [39]. Poor dietary habit, gastrointestinal conditions along with low solar exposure impacts on vitamin $\mathrm{D}$ and dietary mineral absorption resulting in an adverse impact on overall bone health [40].

People with DS have a higher level of health need and experience greater health inequalities in comparison to the general population [41]. Health screening and the identification of specific risks for osteoporosis, prevalent among this cohort, are sparsely investigated and subsequently morbidities can go undetected [42]. Bone health screening is often overlooked [11] [43]. However with no consistent approach to bone screening, evident increased burden of risk factors for osteoporosis yet no clear guidance of the risk burden among people with DS, further investigation is required. Therefore the aim of this paper is to examine the prevalence of risk factors predisposing people with DS to osteoporosis and the relationship of those identified risks to a reported doctor's diagnosis of osteoporosis.

\section{Methods}

The data for this paper was drawn from The Intellectual Disability Supplement to The Irish Longitudinal Study on Ageing (IDS-TILDA) which is a national longitudinal study on aging and intellectual disability. The study commenced in 2009 exploring a number of health, social and life domains of older adults with ID over time (for further information see reference [44]). Data is collected every 3 years and the data presented here is from the first wave of the study. 


\subsection{Sample}

In Ireland people with an ID who are in receipt of services are registered on a National Intellectual Disability Database (NIDD). This database formed the sampling frame employed by the IDS-TILDA study. The inclusion criteria required people to be registered on the NIDD and be aged 40 years or older at the time of the study. IDS-TILDA recruited 753 people of all level of ID and from all living circumstances. A question on etiology of intellectual disability was used to identify the 147 persons with Down syndrome.

\subsection{Ethical Review}

Full ethical approval was granted by Ethics Committees established by the service providers involved in the study and by the Faculty of Health Sciences Ethics Committee, Trinity College Dublin. Consistent with this review, all information was presented to participants in an easy-to-read format in order to obtain informed consent from the participants, and, family or guardians were also invited to support consent or provide agreement where applicable.

\subsection{Measures}

Following examination of the literature, the WHO guidelines and the International Osteoporosis Foundation (IOF) guidelines, common risk factors were identified and matched with comparable data from the IDS-TILDA data collected in Wave 1 (see Table 1).

IDS-TILDA variables such as physical activity and dietary intake were grouped and categorized to further facilitate analysis.

Physical Activity

Ireland has adopted the WHO recommendations [45] of at least 150 minutes of moderate intensity physical activity throughout the week with a focus on strength, balance and gait. Participants in this study were asked to describe their physical activity, both duration and intensity of engagement in terms of mild physical activity (minimal sweating or exertion for a period or $10-20$ minutes such as bowls or golf), moderate physical activity lasting $10-20$ minutes (light sweating or a moderate increase in breathing or heart rate, such as dancing or swimming) and vigorous physical activity lasting 10 - 20 minutes (causing heavy sweating and a notable increase in breathing or heart rate, such as vigorous swimming, running or jogging).

They also reported frequency in terms of more than once a week, once a week, 1 - 3 times a month, or hardly ever or never. Responses were then grouped into three categories (see Table 2). People also identified if they had mobility difficulty by answering a global question on level of difficulty experienced when walking 100 yards.

Dietary Intake

Ireland utilizes a food pyramid of the main food groups [46] reflecting the staple Irish diet. Portion sizes were illustrated for participants. For fruit, vegeta- 
bles, potatoes, bread and cereal, meat, fish, poultry, milk cheese and yogurt, savoury and sweet snacks, fizzy drinks, water, tea, coffee and cordial people indicated the number of portions by frequency per food item i.e. more than four portions per day, 2 - 3 portions per day, 1 portion per day, 5 - 6 portions per week, 2 - 3 portions per week, 1 portion per week, 1 - 3 portions per month or never consuming this item. Each food item was then grouped and categorized in terms of being below, meeting or exceeding recommended daily allowances, taking into consideration age, gender and activity level.

Table 1. Measured risk factors for osteoporosis.

\begin{tabular}{|c|c|}
\hline $\begin{array}{l}\text { Known Risk Factors-IOF, WHO \& } \\
\text { Scientific Literature }\end{array}$ & IDS-TILDA Equivalent Data \\
\hline \multicolumn{2}{|l|}{ Non-Modifiable } \\
\hline Older age & Age \\
\hline Female/menopausal & Gender/Have you gone through the menopause \\
\hline Hypogonadism & $\begin{array}{l}\text { Have you any other chronic health conditions male } \\
\text { gender }\end{array}$ \\
\hline Secondary osteoporosis & Doctors diagnosis of osteoporosis \\
\hline Thyroid disease & Doctors diagnosis of thyroid disease \\
\hline Other endocrine & Doctors diagnosis of rheumatoid arthritis \\
\hline Rheumatoid arthritis & Doctors diagnosis of gastrointestinal reflux \\
\hline GIT conditions & Doctors diagnosis of coeliac disease \\
\hline Coeliac disease ${ }^{\star}$ & Doctors diagnosis of scoliosis \\
\hline Scoliosis* & Doctors diagnosis of diabetes mellitus \\
\hline Diabetes mellitus* & Doctors diagnosis of muscular dystrophy \\
\hline Muscular dystrophy* & Doctors diagnosis of cerebral palsy \\
\hline \multicolumn{2}{|l|}{ Cerebral palsy* } \\
\hline \multicolumn{2}{|l|}{ Modifiable } \\
\hline \multirow[t]{2}{*}{ Sedentary lifestyle } & Levels of physical activity \\
\hline & Mobility_difficulty walking 100 yds \\
\hline Poor calcium intake & Dietary intake and supplementation \\
\hline Vitamin D & Dietary intake, supplementation \\
\hline Low body mass & BMI calculated as weight divided by height squared \\
\hline GIT condition & Doctors diagnosis of chronic constipation ${ }^{\star}$ \\
\hline Anticonvulsant drug use & Anticonvulsant medications \\
\hline Corticosteroid drug use & Corticosteroid medications anxiolytics, \\
\hline $\begin{array}{l}\text { Anxiolytics, sedatives, neuroleptics and } \\
\text { antidepressants }\end{array}$ & $\begin{array}{l}\text { sedatives, neuroleptics and antidepressants } \\
\text { medications }\end{array}$ \\
\hline
\end{tabular}

${ }^{*}$ Conditions with low prevalence rates and subsequently not included in overall table stratified by age and gender.

Table 2. Physical activity categorization.

\begin{tabular}{cl}
\hline Sedentary & $\begin{array}{l}\text { engaged in } 10-20 \text { minutes of mild, moderate or vigorous exercise less } \\
\text { than once a week, } 1-3 \text { times a month or hardly ever or never }\end{array}$ \\
engaged in $10-20$ minutes of moderate exercise once a week and/or \\
vigorous exercise $1-3$ times a month \\
Active & $\begin{array}{l}\text { engaged in } 10-20 \text { minutes of moderate or vigorous exercise more than } \\
\text { once a week }\end{array}$ \\
\hline
\end{tabular}




\subsection{Data Collection}

Data was collected using a two phased approach of a pre-interview questionnaire, which was posted to the participant once consent had been received, and then the main questionnaire was administered via a face-to-face interview. On receipt of consent the field researcher contacted the participant and arranged an appointment for a time and place suitable to the participant. At this point the field researcher forwarded a pre-interview questionnaire which collected demographics, health conditions data, healthcare utilisation, and prescribed medications information. The main interview was conducted as a computer assisted personal interview. The main questionnaire consisted of 17 modules encompassing social, community, physical health, mental health and cognitive assessment [44].

\subsection{Data Analysis}

For the purposes of this study the statistical package for social science (SPSS) v20 was utilized for all analysis. Preliminary analyses were initially carried out with included frequencies, distribution and identification of missing values. With consideration to missing data, valid percentages only are presented throughout the paper. Descriptive statistics were used to analyse the demographic data and overall relationships between variables were explored and stratified by age and gender.

\section{Results}

As may be seen in Table 3, there were more females than males at $56 \%(\mathrm{n}=83)$ vs $44 \%(\mathrm{n}=62)$ respectively. Their ages were predominantly below 65 years, with 3 participants aged 64 years, all of whom were female. Participants lived in a variety of settings, community group home being the largest $(42.9 \%, n=63)$ followed by residential type setting (37.4\%). The majority of participants $(70 \%, \mathrm{n}$ $=95$ ) were within the mild to moderate range of ID. A large number of the cohort had no formal education $(28.6 \%, n=42)$ with just $39.5 \%(n=58)$ reporting they attained some primary education. Whilst the vast majority visited their General Practitioner (GP) regularly very few used specialist services such as endocrinology (2.7\%) or geriatrics (1.4\%).

\subsection{Examining the Risk Factors for Osteoporosis}

\subsubsection{Non-Modifiable Risks}

Just $9.7 \%(\mathrm{n}=14)$ of the participants reported a diagnosis of osteoporosis, all of whom were female, with the majority within the 50 - 64 year age category (see Table 4). Approximately $13 \%(n=19)$ reported having had a fracture, with prevalence twice as high among women $(68.4 \%, \mathrm{n}=14)$ compared to men $(31.6 \%, \mathrm{n}$ $=5)$. Hip fractures were the highest reported type of fracture $(26.5 \%, n=5)$ experienced.

The highest reported health condition was thyroid disease $(37.4 \%, \mathrm{n}=55)$ and again this condition was more predominant among females with the greatest 
prevalence among 50 - 64 year olds. However only $2.7 \%(\mathrm{n}=4)$ attended endocrinological services. Seizure activity was evident $(19.3 \% ; n=28)$, the most common type experienced was tonic clonic seizures $(51.7 \%, \mathrm{n}=15)$ and the majority of those experiencing epilepsy had attended an epilepsy clinic for review within the last year $(75.0 \%, \mathrm{n}=21)$. More females than males reported epilepsy with their rates increasing with age but the reverse was true for males, with a greater prevalence among the younger age category 40 - 49 year olds. As expected anticonvulsant use $(20.4 \%, \mathrm{n}=30)$ was reflective of the levels of epilepsy.

Table 3. Demographics of the participants with Down syndrome.

\begin{tabular}{|c|c|c|}
\hline $\mathrm{N}=147$ & $n$ & $(\%)$ \\
\hline $\begin{array}{l}\text { Gender } \\
\text { Male }\end{array}$ & 65 & $(44.2)$ \\
\hline Female & 82 & $(55.8)$ \\
\hline $\begin{array}{c}\text { AGE } \\
40-49 \text { Years }\end{array}$ & 79 & $(53.7)$ \\
\hline 50 - 64 Years & 65 & $(44.2)$ \\
\hline $65+$ Years & 3 & $(2.0)$ \\
\hline $\begin{array}{l}\text { Living Circumstances } \\
\text { Independent/Semi }\end{array}$ & 29 & $(19.7)$ \\
\hline Community Group Home & 63 & $(42.9)$ \\
\hline Residential & 55 & $(37.4)$ \\
\hline $\begin{array}{l}\text { Level of ID } \\
\quad \text { Mild }\end{array}$ & 20 & $(14.7)$ \\
\hline Moderate & 75 & $(55.1)$ \\
\hline Severe/Profound & 41 & $(30.1)$ \\
\hline $\begin{array}{l}\text { Education Achieved } \\
\text { No Formal Education }\end{array}$ & 42 & $(28.6)$ \\
\hline Primary/Some Primary Level & 58 & $(39.5)$ \\
\hline Secondary & 1 & $(0.7)$ \\
\hline Other & 18 & $(17.0)$ \\
\hline Don't Know & 21 & $(14.2)$ \\
\hline $\begin{array}{l}\text { Health Care Utilisation (within the last year) } \\
\text { General Practitioner (GP) }\end{array}$ & 130 & $(88.4)$ \\
\hline Dental & 85 & $(57.8)$ \\
\hline Optician & 63 & $(42.9)$ \\
\hline Physiotherapy & 34 & $(23.1)$ \\
\hline Dietician & 31 & $(21.1)$ \\
\hline Hearing & 25 & $(17.0)$ \\
\hline Endocrinologist & 4 & $(2.7)$ \\
\hline Geriatrician & 2 & (1.4) \\
\hline
\end{tabular}


Table 4. Non modifiable and modifiable risk factors associated with low bone mineral density according to gender and age.

\begin{tabular}{|c|c|c|c|c|c|c|c|c|c|c|c|c|c|c|}
\hline \multirow{3}{*}{ Variable } & \multirow{2}{*}{\multicolumn{2}{|c|}{ Total $N=147$}} & \multicolumn{6}{|c|}{ Women $\mathrm{n}=83$} & \multicolumn{6}{|c|}{ Men $n=64$} \\
\hline & & & \multicolumn{2}{|c|}{$\begin{array}{c}40-49 \text { years } \\
\mathrm{n}=39\end{array}$} & \multicolumn{2}{|c|}{$\begin{array}{c}50-64 \text { years } \\
n=40\end{array}$} & \multicolumn{2}{|c|}{$\begin{array}{c}65+\text { years } \\
n=3\end{array}$} & \multicolumn{2}{|c|}{$\begin{array}{c}40-49 \text { years } \\
\mathrm{n}=40\end{array}$} & \multicolumn{2}{|c|}{$\begin{array}{c}50-64 \text { years } \\
n=26\end{array}$} & \multicolumn{2}{|c|}{$\begin{array}{c}65+\text { years } \\
\mathrm{n}=0\end{array}$} \\
\hline & $f$ & $\%$ & $f$ & $\%$ & $f$ & $\%$ & $f$ & $\%$ & $f$ & $\%$ & $f$ & $\%$ & $f$ & $\%$ \\
\hline \multicolumn{15}{|l|}{ Non Modifiable } \\
\hline History of Osteoporosis & 14 & $(9.7)$ & 3 & $(7.7)$ & 11 & $(27.5)$ & 0 & $(0.0)$ & 0 & $(0.0)$ & 0 & $(0.0)$ & 0 & $(0.0)$ \\
\hline Thyroid Disease & 55 & $(37.4)$ & 13 & $(33.3)$ & 24 & $(60.0)$ & 0 & $(0.0)$ & 11 & $(27.5)$ & 6 & $(25.9)$ & 0 & $(0.0)$ \\
\hline Epilepsy & 28 & $(19.3)$ & 3 & $(7.7)$ & 13 & $(32.5)$ & 1 & $(33.3)$ & 7 & $(17.5)$ & 4 & $(16.0)$ & 0 & $(0.0)$ \\
\hline Anticonvulsant Drug Use & 30 & $(20.4)$ & 4 & $(10.3)$ & 12 & $(30.0)$ & 1 & $(33.3)$ & 7 & $(17.5)$ & 6 & $(24.0)$ & 0 & $(0.0)$ \\
\hline Experienced Menopause & 50 & $(61.0)$ & 15 & $(39.5)$ & 33 & $(80.5)$ & 2 & $(66.7)$ & - & - & - & - & - & - \\
\hline Don't Know & 13 & $(15.9)$ & 5 & $(13.2)$ & 7 & $(17.1)$ & 1 & $(33.3)$ & - & - & - & - & - & - \\
\hline $\begin{array}{l}\text { Mobility (walking } 100 \text { yds.) } \\
\text { No Difficulty }\end{array}$ & 107 & $(72.8)$ & 32 & $(82.1)$ & 22 & $(53.7)$ & 1 & $(33.3)$ & 34 & $(85.0)$ & 18 & $(75.0)$ & 0 & $(0.0)$ \\
\hline Some Difficulty & 17 & $(11.6)$ & 4 & $(10.3)$ & 9 & $(22.0)$ & 0 & $(0.0)$ & 3 & $(7.5)$ & 1 & $(4.2)$ & 0 & $(0.0)$ \\
\hline A Lot of Difficulty & 7 & $(4.8)$ & 0 & $(0.0)$ & 3 & $(7.3)$ & 0 & $(0.0)$ & 2 & $(5.0)$ & 2 & $(8.3)$ & 0 & $(0.0)$ \\
\hline Cannot Do at All & 16 & $(10.9)$ & 3 & $(7.3)$ & 7 & $(17.1)$ & 2 & $(66.7)$ & 1 & $(2.5)$ & 3 & $(12.5)$ & 0 & $(0.0)$ \\
\hline \multicolumn{15}{|l|}{ Modifiable* $^{*}$} \\
\hline $\begin{array}{c}\text { Body Mass Index (BMI) } \\
\text { Underweight }\end{array}$ & 2 & 1.7 & 1 & $(3.0)$ & 0 & $(0.0)$ & 0 & $(0.0)$ & 0 & $(0.0)$ & 1 & $(5.0)$ & 0 & $(0.0)$ \\
\hline Healthy Weight & 34 & 29.6 & 5 & 15.2 & 11 & 42.3 & 0 & 0.0 & 12 & 34.3 & 6 & 30.0 & 0 & $(0.0)$ \\
\hline Overweight & 31 & 27.0 & 11 & 33.3 & 3 & 11.5 & 1 & 100.0 & 8 & 22.9 & 8 & 40.0 & 0 & $(0.0)$ \\
\hline Obese & 48 & 41.7 & 16 & 48.5 & 12 & 46.2 & 0 & 0.0 & 15 & 42.9 & 5 & 25.0 & 0 & $(0.0)$ \\
\hline Chronic Constipation & 10 & $(6.8)$ & 0 & $(0.0)$ & 6 & $(15.0)$ & 0 & $(0.0)$ & 3 & 7.5 & 1 & $(4.0)$ & 0 & $(0.0)$ \\
\hline Gastroesophageal Reflux & 10 & $(6.8)$ & 3 & $(7.7)$ & 3 & $(7.5)$ & 1 & $(33.3)$ & 2 & $(5.0)$ & 1 & $(4.0)$ & 0 & $(0.0)$ \\
\hline History of Smoking & 7 & $(4.8)$ & 1 & $(2.6)$ & 2 & $(5.0)$ & 0 & $(0.0)$ & 3 & $(7.5)$ & 1 & $(4.0)$ & 0 & $(0.0)$ \\
\hline History of Alcohol Intake & 65 & $(44.2)$ & 19 & $(48.7)$ & 14 & $(35.0)$ & 1 & $(33.3)$ & 18 & $(45.0)$ & 13 & $(52.0)$ & 0 & $(0.0)$ \\
\hline >2 Drinks/Day 3 - 4 Days a Week & 2 & $(3.1)$ & 0 & $(0.0)$ & 0 & $(0.0)$ & 0 & $(0.0)$ & 1 & $(5.7)$ & 1 & $(5.9)$ & 0 & $(0.0)$ \\
\hline Hypnotics and Sedatives & 14 & $(9.5)$ & 3 & $(7.6)$ & 5 & $(12.5)$ & 0 & $(0.0)$ & 4 & $(10.0)$ & 2 & $(8.0)$ & 0 & $(0.0)$ \\
\hline Antidepressants & 26 & $(17.7)$ & 3 & $(7.6)$ & 10 & $(25.0)$ & 0 & $(0.0)$ & 9 & $(22.5)$ & 4 & $(16.0)$ & 0 & $(0.0)$ \\
\hline Anxiolytics & 17 & (11.6) & 4 & $(10.3)$ & 4 & $(10.0)$ & 0 & $(0.0)$ & 4 & $(10.0)$ & 5 & $(20.0)$ & 0 & $(0.0)$ \\
\hline
\end{tabular}

Among female participants over $60 \%$ had experienced the menopause with almost a fifth of those reporting early menarche (before the age of 50 years), mean age of onset 44.8 years $\mathrm{SD} \pm 4.27$ with a range of $38-53$ years respectively. A further $21 \%(\mathrm{n}=31)$ were unsure if they had experienced the menopause. Over $25 \%(n=40)$ of participants reported some level of difficulty with walking 100 yards of which over $10 \%(\mathrm{n}=16)$ could not walk this distance at all. Middle 
aged women (50 - 64 years) presented with the greatest amount of difficulty $(46.4 \%, \mathrm{n}=19)$.

\subsubsection{Modifiable Conditions}

In terms of BMI, the majority of participants were within the overweight and obese categories at $68.7 \%(n=79)$ with only $29.6 \%$ within the healthy weight category and just 2 participants identified as underweight. Almost 7\% reported chronic constipation with a similar number reporting gastric reflux $(6.8 \%, \mathrm{n}=$ $10)$. Few had a history of smoking $(4.8 \%, \mathrm{n}=7)$ with even fewer consuming excessive amounts of alcohol $(3.1 \%, \mathrm{n}=2)$. Reported levels of hypnotic \& sedative, antidepressant and anxiolytic use were 9.5\% $(n=14), 17.7 \%(n=26)$ and $11.6 \%$ $(n=17)$ respectively. No participants with DS were taking corticosteroids, medicines noted by the WHO as among the higher contributing risk to osteoporosis development. See Table 4 for overall non-modifiable and modifiable risks stratified by age and gender.

\section{Dietary Behaviours}

The majority of people ate three meals a day interspersed with snacks. Many people with DS did not consume the recommended daily 5 portions a day of fruits and vegetables $(87.7 \%, \mathrm{n}=128)$, dairy $(36.3 \%, \mathrm{n}=53)$ and carbohydrate $(23.8 \%, \mathrm{n}=35)$. With regards to sweet/fizzy drink/candy intake, just over $50 \%$ met the suggested daily amount with the remaining 50\% exceeding recommendations, with men more likely to exceed. Also, almost $43 \%(n=35)$ of women did not consume the recommended amounts of carbohydrate intake on a daily basis. Overall the vast majority of men and women did not achieve daily recommendations for fruit and veg with men $(93.8 \%, n=60)$ faring worst. Of concern in terms of bone health implications, over a third of both women and men (34.1\% $\mathrm{n}=28$ and $39.1 \%, \mathrm{n}=25$ respectively) did not attain the daily recommendations for dairy intake, a healthy source of calcium (see Table 5).

Physical Activity

As outlined in Table 6 a large proportion of participants did not engaged in physical activity at levels to accrue health benefit with $51 \%(n=76)$ of participants doing very little or no physical activity. This was particularly evident among the over 50 age group where just $38 \%(n=26)$ engaged in active or semi-active physical activity and even among the 40 - 49 year olds levels of active engagement were very low with just $10.1 \%(n=8)$ reporting active levels of physical activity. Men led relatively inactive lifestyles with $54 \%(n=35)$ falling within the sedentary category and $40 \%(n=26)$ reaching only the semi-active level. Inactivity was also associated with level of ID with $83 \%$ of those with severe/profound ID being relatively inactive.

\section{Other Factors Impacting on Bone Health}

Although numbers were small additional health conditions, as outlined in $\mathrm{Ta}$ ble 7, were reported by participants with DS that directly or indirectly affect bone health. These included coeliac disease at 5.5\% $(n=8)$, scoliosis $(2.7 \%, n=$ $4)$, diabetes $(1.4 \%, \mathrm{n}=2)$, muscular dystrophy $(1.4 \%, \mathrm{n}=2)$ and cerebral palsy 
$(0.7 \%, \mathrm{n}=1)$. Conditions indirectly affecting bone health were notably higher, these included cataracts and Alzheimer's dementia at 29.9\% $(n=44)$ and $15.6 \%$ $(n=23)$ respectively. Finally only $17 \%(n=25)$ of all the participants reported taking vitamin D supplementation.

Reported Bone Density Screening

Only 7 people reported having had a dual-energy X-ray absorptiometry (DXA) scan and just 3 within the last 2 years. No men reported having had a scan no matter what age. Further, no person with a history of fracture reported having had a DXA and screening levels were low among those reporting risk factors such as experience of menopause $(n=50)$, thyroid disease $(n=55)$ and epilepsy $(\mathrm{n}=28)$ at $30 \%(\mathrm{n}=6), 21.4 \%(\mathrm{n}=6)$ and $30.8 \%(\mathrm{n}=4)$ respectively. For the DXA question there were only 87 participant answers.

Table 5. Food group intake recommendations according to gender distribution.

\begin{tabular}{|c|c|c|c|c|c|c|c|c|c|c|c|c|}
\hline & \multicolumn{6}{|c|}{ Female $(\mathrm{n}=82)$} & \multicolumn{6}{|c|}{ Male $(n=65)$} \\
\hline & \multirow{2}{*}{\multicolumn{2}{|c|}{$\begin{array}{c}\text { Below } \\
\text { Requirement }\end{array}$}} & \multirow{2}{*}{\multicolumn{2}{|c|}{$\begin{array}{l}\text { Meets } \\
\text { equirement }\end{array}$}} & \multirow{2}{*}{\multicolumn{2}{|c|}{$\begin{array}{c}\text { Exceeds } \\
\text { Requirement }\end{array}$}} & \multirow{2}{*}{\multicolumn{2}{|c|}{$\begin{array}{c}\text { Below } \\
\text { Requirement }\end{array}$}} & \multicolumn{2}{|c|}{ Meets } & \multicolumn{2}{|c|}{ Exceeds } \\
\hline & & & & & & & & & Requ & ement & Requ & rement \\
\hline & $f$ & $\%$ & $f$ & $\%$ & & $\%$ & $f$ & $\%$ & $f$ & $\%$ & $f$ & $\%$ \\
\hline Carbohydrates & 35 & 42.7 & 38 & 46.3 & 9 & 11.0 & - & - & 65 & 100 & - & - \\
\hline Fruit and Veg & 68 & 82.9 & 12 & 14.6 & 2 & 2.4 & 60 & 93.8 & 4 & 6.3 & - & - \\
\hline Dairy & 28 & 34.1 & 46 & 56.1 & 8 & 9.8 & 25 & 39.1 & 36 & 56.3 & 3 & 4.7 \\
\hline Meat & 2 & 2.4 & 78 & 95.1 & 2 & 2.4 & 4 & 6.3 & 60 & 93.8 & - & - \\
\hline Sweets & - & - & 47 & 58.0 & 34 & 42.0 & - & - & 25 & 40.3 & 47 & 59.7 \\
\hline
\end{tabular}

Table 6. Levels of physical activity engagement according to gender, age \& level of ID.

\begin{tabular}{|c|c|c|c|c|c|c|c|c|}
\hline \multirow[b]{2}{*}{ Age Groups } & & \multicolumn{2}{|c|}{ Active } & \multicolumn{2}{|c|}{ Semi-active } & \multicolumn{2}{|c|}{ Sedentary } & \multirow{2}{*}{$\begin{array}{l}\text { No. in } \\
\text { sample }\end{array}$} \\
\hline & & $f$ & $\%$ & $f$ & $\%$ & $f$ & $\%$ & \\
\hline \multirow[t]{3}{*}{ Female $(\mathrm{n}=82)$} & $40-49$ & 5 & 12.8 & 20 & 51.3 & 14 & 35.9 & 39 \\
\hline & $50-64$ & 1 & 2.5 & 14 & 35.0 & 25 & 62.5 & 40 \\
\hline & $65+$ & - & 0.0 & 1 & 33.3 & 2 & 66.7 & 3 \\
\hline \multirow[t]{3}{*}{ Male $(\mathrm{n}=65)$} & $40-49$ & 3 & 7.5 & 17 & 42.5 & 20 & 50.0 & 40 \\
\hline & $50-64$ & 1 & 4.0 & 9 & 36.0 & 15 & 60.0 & 25 \\
\hline & $65+$ & - & 0.0 & - & 0.0 & - & 0.0 & - \\
\hline \multirow[t]{3}{*}{ Level of ID $(n=136)^{*}$} & Mild & 1 & 5.0 & 14 & 70.0 & 5 & 25.0 & 20 \\
\hline & Moderate & 8 & 10.7 & 34 & 45.3 & 33 & 44.0 & 75 \\
\hline & Severe/Profound & - & 0.0 & 7 & 17.1 & 34 & 82.9 & 41 \\
\hline
\end{tabular}

${ }^{*}$ Missing obs $=11\left(\right.$ People who did not identify their level of $\left.\mathrm{ID}^{1}\right)$.

${ }^{1}$ Little's MCAR test fails to reject the null hypothesis that the data is missing at random and therefore there is no evidence that the missing data is affecting the findings-p-value $=0.328$. 
Table 7. Other health conditions directly and indirectly effecting bone health.

\begin{tabular}{ccc}
\hline Other health conditions directly effecting bone health & \\
\hline & $f$ & $\%$ \\
\hline Coeliac & 8 & $(5.5)$ \\
Scoliosis & 4 & $(2.7)$ \\
Diabetes & 2 & $(1.4)$ \\
Muscular dystrophy & 2 & $(1.4)$ \\
Cerebral palsy & 1 & $(0.7)$ \\
Health conditions indirectly effecting bone health & & \\
Cataracts & 44 & $(29.9)$ \\
Alzheimer's dementia & 23 & $(15.6)$ \\
Asthma & 7 & $(4.8)$ \\
Cancer & 2 & $(1.4)$ \\
Vitamin D supplementation & 25 & $(17.0)$ \\
\hline
\end{tabular}

\section{Discussion}

As was previously noted, DS in itself has been shown to be a risk factor for the presence of osteoporosis and osteopenia [11] [15] [16] [47] [48] [49]. Findings here concur that people with DS are a high "at risk" group. The confirmed prevalence of thyroid disease, early menopause, specific medications that interfere with bone metabolism, and levels of inactivity and sedentary lifestyle, all culminate in increased likelihood of developing osteoporosis or osteopenia.

Osteoporosis is receptive to treatment and preventable; however in this study active health promotion was not evident. For example, physical activity engagement at levels that would accrue health benefit was not evident. Although rates of physical activity were very low, some participation is better than none and promoting engagement in exercise that is fun, enjoyable and diverse needs to be encouraged. With imagination and resourcefulness people with DS can be encouraged to engage, however as Heller and colleagues indicate [50], it is their carers and supporters that make the difference and lead by example.

Attendance at specialists such as an endocrinologist was also low, and although people attended their GP regularly the levels of calcium and vitamin D supplementation was low. In Ireland, a northern hemisphere country, it is acknowledged that sunlight levels are considered low and supplementation is suggested [8]. Genant and colleagues advised that further pharmacological interventions ought to be targeted at those with highest risk of fracture but little evidence of this was found for people with DS [8]. The findings that overall dietary balance in the sample was poor, suggests future research ought to examine whether dietary status is an issue of poor choices or a lack of awareness among health professionals and carers. Considering that many of the participants in the study lived in supported settings, either community group homes or residential 
settings, where the daily dietary decision making may be taken out of their hands, these findings support the implementation of education to improve overall diet and consideration for supplementation for people with DS.

Levels of diagnosed osteoporosis were not particularly high, but low screening rates with high presence of risk factors perhaps suggest hidden undiagnosed disease, especially among males. No male reported the presence of osteoporosis or osteopenia nor having had a DXA despite risk factors including the prevalence of hypogonadism among men with DS. In addition $13.4 \%$ of the participants in this study reported having experienced a fracture with hip fractures occurring at twice the rate reported by those in the general population study The Irish Longitudinal Study on Ageing Wave 1 results (TILDA) [51]; yet only 8\% reported having had a DXA scan. Overall the attendance for DXA is concerning and perhaps a possible explanation maybe that people with DS are fearful of engaging and therefore non-compliant, may have physical deformities that prevents appropriate positioning in the scanner or it may simply be a case where the carer is not aware of the risks people with DS face. Consideration ought to be given to the, Van Allen and colleagues [52] suggestion, and endorsed by Carfi and colleagues [16] of regular systematic screening for people with DS especially as the WHO also recommends such screening for all individuals with one or more strong risk factors. They would argue menopause is one such factor, and as can be seen here, a large number of the women had gone through menopause, and, perhaps hypogonadism among males could be another. Whilst they do concede that population screening is not a cost effective approach, making more widely available techniques such as quantitative ultrasound ought to be explored [8]. The TILDA study included bone screening for general population participants, however confirmation of the doctor's diagnosis of osteoporosis was much less than numbers found to meet criteria through screening. In the TILDA study they found that $86 \%(\mathrm{n}=1365)$ with objectively measured evidence of osteopenia and $72 \%(\mathrm{n}=218)$ osteoporosis did not have a doctor's confirmation of diagnosis [53]. Overall greater surveillance of health risks is seen as a way to improve the health status of older adults with ID [54].

It must be highlighted that people with DS do experience communication challenges and expressing their health needs can often pose challenges. However, as people with DS age their increased vulnerability to the development of Alzheimer's dementia is well recognized and perhaps a contributing factor to other clinical signs and symptoms of underlying medical conditions going unrecognized [55]. Alzheimer's dementia also increases the person's susceptibility to falling thus increasing the risk of fracture. Instigating measures to prevent and address osteoporosis at an early stage would be preferable, along with increasing carer's awareness of the potential and insidious nature of osteoporosis along with its disagreeable consequences.

Limitations to this paper must be recognized; the group studied is larger than most published papers on DS and were drawn from a representative sample of 
people with ID but there were small numbers in some of the subgroups considered. Further, the presence of osteoporosis was based on a doctor's reported diagnosis and was not objectively measured however future waves are addressing this concern.

\section{Conclusion}

Evidence emerges from this study that identified risks which include thyroid disease, epilepsy and its associated medications, inactivity and dietary imbalance are at levels which, based on prior general and DS population studies, would increase the risk of developing osteoporosis. Coupled with the predisposition that already exists among people with DS this is a recipe for future deleterious consequences. Considering prior reports of differences between self-reported and objectively measured osteoporosis, the high prevalence of risk factors among people with DS found here supports further objective investigation of symptoms, and rigorous risk surveillance along with support and encouragement to strengthen positive behaviours such as increased participation in physical activities, to contribute to the promotion of good bone health.

\section{Acknowledgements}

The authors would like to thank the people with intellectual disability who participated in this study, their families, carers, the services involved, the IDS-TILDA Scientific Advisory Committee and the Intellectual Disability Consultative Groups for their support. The authors would also like to acknowledge funding for the IDS-TILDA study from the Health Research Board and the Department of Health. The views expressed are those of the authors and are not necessarily those of the Department of Health, The Health Research Board or Trinity College Dublin. This research was funded by the Department of Health in Ireland and managed by the Health Research Board. The funding bodies did not play a role in the study design or writing of the manuscript.

\section{Conflicts of Interest}

The authors declare no conflicts of interest regarding the publication of this paper.

\section{References}

[1] Kanis, J., McCloskey, E., Johansson, H., Cooper, C., Rizzoli, R. and Reginster, J.-Y. (2013) European Guidance for the Diagnosis and Management of Osteoporosis in Postmenopausal Women. Osteoporosis International, 24, 23-57. https://doi.org/10.1007/s00198-012-2074-y

[2] World Health Organization (1994) Assessment of Fracture Risk and Its Application to Screening for Postmenopausal Osteoporosis: Report of a WHO Study Group' (Meeting Held in Rome from 22 to 25 June 1992). WHO, Geneva, 1-129.

[3] Cooper, C. (2014) The Lifecourse Epidemiology of Musculoskeletal Ageing. Osteoporosis International, 25, S101-S102. 
[4] Datta, H., Ng, W., Walker, J., Tuck, S. and Varanasi, S. (2008) The Cell Biology of Bone Metabolism. Journal of Clinical Pathology, 61, 577-587. https://doi.org/10.1136/jcp.2007.048868

[5] Kanis, J., Black, D., Cooper, C., Dargent, P., Dawson-Hughes, B., De Laet, C., Jonsson, B., et al. (2002) A New Approach to the Development of Assessment Guidelines for Osteoporosis. Osteoporosis International, 13, 527-536. https://doi.org/10.1007/s001980200069

[6] World Health Organization (2002) Active Ageing: A Policy Framework. WHO, Geneva, Switzerland. http://www.who.int/ageing/publications/active_ageing/en/

[7] Beerhorst, K., de Krom, M., Aldenkamp, B. and Tan, F. (2009) Severe Early Onset Osteoporosis in Five Young Men with an Intellectual Disability, Epilepsy and Long-Term Antiepileptic Drug Use. Epilepsia, 50, 77.

[8] Genant, H.K., Cooper, C., Poor, G., Reid, I., Ehrlich, G., Kanis, J., Bonjour, J.-P., et al. (1999) Interim Report and Recommendations of the World Health Organization Task-Force for Osteoporosis. Osteoporosis International, 10, 259-264. https://doi.org/10.1007/s001980050224

[9] Kanis, J.A., Johansson, H., Oden, A. and McCloskey, E.V. (2009) Assessment of Fracture Risk. European Journal of Radiology, 71, 392-397. https://doi.org/10.1016/j.ejrad.2008.04.061

[10] Kanis, J.A. (1994) Assessment of Fracture Risk and Its Application to Screening for Postmenopausal Osteoporosis: Synopsis of a WHO Report. Osteoporosis International, 4, 368-381. https://doi.org/10.1007/BF01622200

[11] Angelopoulou, N., Souftas, V., Sakadamis, A. and Mandroukas, K. (1999) Bone Mineral Density in Adults with Down's Syndrome. European Radiology, 9, 648-651. https://doi.org/10.1007/s003300050726

[12] Geijer, J.R., Stanish, H.I., Draheim, C.C. and Dengel, D.R. (2014) Bone Mineral Density in Adults with Down Syndrome, Intellectual Disability, and Nondisabled Adults. American Journal on Intellectual and Developmental Disabilities, 119, 107-114. https://doi.org/10.1352/1944-7558-119.2.107

[13] González-Agüero, A., Vicente-Rodriguez, G., Moreno, L. and Casajus, J. (2011) Bone Mass in Male and Female Children and Adolescents with Down Syndrome. Osteoporosis International, 22, 2151-2157. https://doi.org/10.1007/s00198-010-1443-7

[14] Guijarro, M., Valero, C., Paule, B., Gonzalez-Macias, J. and Riancho, J.A. (2008) Bone Mass in Young Adults with Down Syndrome. Journal of Intellectual Disability Research, 52, 182-189. https://doi.org/10.1111/j.1365-2788.2007.00992.x

[15] McKelvey, K., Fowler, T., Akel, N., Kelsay, J., Gaddy, D., Wenger, G. and Suva, L. (2013) Low Bone Turnover and Low Bone Density in a Cohort of Adults with Down Syndrome. Osteoporosis International, 24, 1333-1338. https://doi.org/10.1007/s00198-012-2109-4

[16] Carfi, A., Liperoti, R., Fusco, D., Giovannini, S., Brandi, V., Vetrano, D.L., Gravina, E.M., et al. (2017) Bone Mineral Density in Adults with Down Syndrome. Osteoporosis International, 28, 2929-2934. https://doi.org/10.1007/s00198-017-4133-X

[17] Dierssen, M. and de la Torre Fornell, R. (2012) Down Syndrome: From Understanding the Neurobiology to Therapy. Vol. 197, Elsevier, Amsterdam.

[18] Glasson, E., Sullivan, S., Hussain, R., Petterson, B., Montgomery, P. and Bittles, A. (2002) The Changing Survival Profile of People with Down's Syndrome: Implications for Genetic Counselling. Clinical Genetics, 62, 390-393. 
https://doi.org/10.1034/j.1399-0004.2002.620506.x

[19] Michael, J. (2008) Healthcare for All: Report of the Independent Inquiry into Access to Healthcare for People with Learning Disabilities. London.

[20] Seeman, E. (1999) The Structural Basis of Bone Fragility in Men. Bone, 25, 143-147. https://doi.org/10.1016/S8756-3282(99)00117-9

[21] Schupf, N., Zigman, W., Kapell, D., Lee, J., Kline, J. and Levin, B. (1997) Early Menopause in Women with Down's Syndrome. Journal of Intellectual Disability Research, 41, 264-267. https://doi.org/10.1111/j.1365-2788.1997.tb00706.x

[22] Bittles, A.H., Bower, C., Hussain, R. and Glasson, E.J. (2007) The Four Ages of Down Syndrome. The European Journal of Public Health, 17, 221-225. https://doi.org/10.1093/eurpub/ckl103

[23] Glasson, E., Dye, D. and Bittles, A.H. (2014) The Triple Challenges Associated with Age-Related Comorbidities in Down Syndrome. Journal of Intellectual Disability Research, 58, 393-398. https://doi.org/10.1111/jir.12026

[24] Roth, G.M., Sun, B., Greensite, F.S., Lott, I.T. and Dietrich, R.B. (1996) Premature Aging in Persons with Down Syndrome: MR Findings. American Journal of Neuroradiology, 17, 1283-1289.

[25] Karlsson, B., Gustafsson, J., Hedov, G., Ivarsson, S. and Annerén, G. (1998) Thyroid Dysfunction in Down's Syndrome: Relation to Age and Thyroid Autoimmunity. Archives of Disease in Childhood, 79, 242-245. https://doi.org/10.1136/adc.79.3.242

[26] Prasher, V. (1999) Down Syndrome and Thyroid Disorders: A Review. Down Syndrome Research and Practice, 6, 25-42. https://doi.org/10.3104/reviews.95

[27] Waung, J.A., Bassett, J.D. and Williams, G.R. (2012) Thyroid Hormone Metabolism in Skeletal Development and Adult Bone Maintenance. Trends in Endocrinology \& Metabolism, 23, 155-162. https://doi.org/10.1016/j.tem.2011.11.002

[28] Villani, E., Onder, G., Carfi, A., Di Segni, C., Raimondo, S., Silvestrini, A., Mancini, A., et al. (2016) Thyroid Function and Its Implications in Oxidative Stress Influencing the Pathogenesis of Osteoporosis in Adults with Down Syndrome: A Cohort Study. Hormone and Metabolic Research, 48, 565-570.

https://doi.org/10.1055/s-0042-112127

[29] McCarron, M., Gill, M., McCallion, P. and Begley, C. (2005) Health Co-Morbidities in Ageing Persons with Down Syndrome and Alzheimer's Dementia. Journal of Intellectual Disability Research, 49, 560-566. https://doi.org/10.1111/j.1365-2788.2005.00704.x

[30] Torr, J., Strydom, A., Patti, P. and Jokinen, N. (2010) Aging in Down Syndrome: Morbidity and Mortality. Journal of Policy and Practice in Intellectual Disabilities, 7, 70-81. https://doi.org/10.1111/j.1741-1130.2010.00249.x

[31] Penedo, F.J. and Dahn, J.R. (2005) Exercise and Well-Being: A Review of Mental and Physical Health Benefits Associated with Physical Activity. Current Opinion in Psychiatry, 18, 189-193. https://doi.org/10.1097/00001504-200503000-00013

[32] Schwab, P. and Scalapino, K. (2011) Exercise for Bone Health: Rationale and Prescription. Current Opinion in Rheumatology, 23, 137-141. https://doi.org/10.1097/BOR.0b013e3283434501

[33] Matute-Llorente, Á., González-Agüero, A., Gómez-Cabello, A., Vicente-Rodríguez, G. and Casajús, J.A. (2013) Decreased Levels of Physical Activity in Adolescents with Down Syndrome Are Related with Low Bone Mineral Density: A Cross-Sectional Study. BMC Endocrine Disorders, 13, 22. https://doi.org/10.1186/1472-6823-13-22

[34] Rubin, S.S., Rimmer, J.H., Chicoine, B., Braddock, D. and McGuire, D.E. (1998) 
Overweight Prevalence in Persons with Down Syndrome. Mental Retardation, 36, 175-181. https://doi.org/10.1352/0047-6765(1998)036<0175:OPIPWD>2.0.CO;2

[35] de Asua, D.R., Parra, P., Costa, R., Moldenhauer, F. and Suarez, C. (2014) Evaluation of the Impact of Abdominal Obesity on Glucose and Lipid Metabolism Disorders in Adults with Down Syndrome. Research in Developmental Disabilities, 35, 2942-2949. https://doi.org/10.1016/j.ridd.2014.07.038

[36] Wortsman, J., Matsuoka, L.Y., Chen, T.C., Lu, Z. and Holick, M.F. (2000) Decreased Bioavailability of Vitamin D in Obesity. The American Journal of Clinical Nutrition, 72, 690-693. https://doi.org/10.1093/ajcn/72.3.690

[37] Compston, J.E., Watts, N.B., Chapurlat, R., Cooper, C., Boonen, S., Greenspan, S., Lindsay, R., et al. (2011) Obesity Is Not Protective against Fracture in Postmenopausal Women: GLOW. The American Journal of Medicine, 124, 1043-1050. https://doi.org/10.1016/j.amjmed.2011.06.013

[38] Robertson, J., Emerson, E., Gregory, N., Hatton, C., Turner, S., Kessissoglou, S. and Hallam, A. (2000) Lifestyle Related Risk Factors for Poor Health in Residential Settings for People with Intellectual Disabilities. Research in Developmental Disabilities, 21, 469-486. https://doi.org/10.1016/S0891-4222(00)00053-6

[39] Böhmer, C., Taminiau, J., Klinkenberg-Knol, E. and Meuwissen, S. (2001) The Prevalence of Constipation in Institutionalized People with Intellectual Disability. Journal of Intellectual Disability Research, 45, 212-218. https://doi.org/10.1046/j.1365-2788.2001.00300.x

[40] Frighi, V., Morovat, A., Stephenson, M.T., White, S.J., Hammond, C.V. and Goodwin, G.M. (2014) Vitamin D Deficiency in Patients with Intellectual Disabilities: Prevalence, Risk Factors and Management Strategies. The British Journal of Psychiatry, 205, 458-464. https://doi.org/10.1192/bjp.bp.113.143511

[41] Cooper, S.-A., Melville, C. and Morrison, J. (2004) People with Intellectual Disabilities: Their Health Needs Differ and Need to Be Recognised and Met. British Medical Journal, 329, 414. https://doi.org/10.1136/bmj.329.7463.414

[42] Piachaud, J., Rohde, J. and Pasupathy, A. (1998) Health Screening for People with Down's Syndrome. Journal of Intellectual Disability Research, 42, 341-345. https://doi.org/10.1046/j.1365-2788.1998.00142.x

[43] Srikanth, R., Cassidy, G., Joiner, C. and Teeluckdharry, S. (2011) Osteoporosis in People with Intellectual Disabilities: A Review and a Brief Study of Risk Factors for Osteoporosis in a Community Sample of People with Intellectual Disabilities. Journal of Intellectual Disability Research, 55, 53-62. https://doi.org/10.1111/j.1365-2788.2010.01346.x

[44] McCarron, M., Swinburne, J., Burke, E., McGlinchey, E., Andrews, V., Mulryan, N., McCallion, P., et al. (2011) Growing Older with an Intellectual Disability in Ireland 2011: First Results from the Intellectual Disability Supplement to the Irish Longitudinal Study on Ageing (IDS-TILDA). School of Nursing and Midwifery, Trinity College Dublin. https://www.tcd.ie/tcaid/assets/pdf/idstildareport2011.pdf

[45] World Health Organization (2010) Global Recommendations on Physical Activity for Health.

http://apps.who.int/iris/bitstream/handle/10665/44399/9789241599979_eng.pdf;jses sionid=E120A4ACB1F0B5FE526034201140A53E? sequence $=1$

[46] Department of Health and Children (2012) Your Guide to Healthy Eating Using the Food Pyramid. http://www.lenus.ie/hse/handle/10147/305177

[47] Angelopoulou, N., Matziari, C., Tsimaras, V., Sakadamis, A., Souftas, V. and Mandroukas, K. (2000) Bone Mineral Density and Muscle Strength in Young Men with 
Mental Retardation (with and without Down Syndrome). Calcified Tissue International, 66, 176-180. https://doi.org/10.1007/s002230010035

[48] Kao, C., Chen, C., Wang, S. and Yeh, S. (1992) Bone Mineral Density in Children with Down's Syndrome Detected by Dual Photon Absorptiometry. Nuclear Medicine Communications, 13, 773-775. https://doi.org/10.1097/00006231-199213100-00012

[49] Sepúlveda, D., Allison, D.B., Gomez, J.E., Kreibich, K., Brown, R.A., Pierson Jr., R.N. and Heymsfield, S.B. (1995) Low Spinal and Pelvic Bone Mineral Density among Individuals with Down Syndrome. American Journal of Mental Retardation, 100, 109-114.

[50] Heller, T., Hsieh, K. and Rimmer, J. (2003) Barriers and Supports for Exercise Participation among Adults with Down Syndrome. Journal of Gerontological Social Work, 38, 161-178. https://doi.org/10.1300/J083v38n01_03

[51] Barrett, A., Burke, H., Cronin, H., Hickey, A., Kamiya, Y., Kenny, R.A., Morgan, K., et al. (2011) Fifty plus in Ireland 2011: First Results from the Irish Longitudinal Study on Ageing (TILDA).

https://tilda.tcd.ie/publications/reports/pdf/w1-key-findings-report/Tilda_Master_F irst_Findings_Report.pdf

[52] Van Allen, M.I., Fung, J. and Jurenka, S.B. (1999) Health Care Concerns and Guidelines for Adults with Down Syndrome. American Journal of Medical Genetics Part $A, 89,100-110$. https://doi.org/10.1002/(SICI)1096-8628(19990625)89:2<100::AID-AJMG8>3.0.CO; $2-\mathrm{N}$

[53] Cronin, H., O’Regan, C. and Kenny, R.A. (2011) Physical and Behavioural Health of Older Irish Adults. Fifty Plus in Ireland, 73.

https://tilda.tcd.ie/publications/reports/pdf/w1-key-findings-report/Chapter5.pdf

[54] Haveman, M., Heller, T., Lee, L., Maaskant, M., Shooshtari, S. and Strydom, A. (2010) Major Health Risks in Aging Persons with Intellectual Disabilities: An Overview of Recent Studies. Journal of Policy and Practice in Intellectual Disabilities, 71, 59-69. https://doi.org/10.1111/j.1741-1130.2010.00248.x

[55] McCarron, M. and Lawlor, B. (2003) Responding to the Challenges of Ageing and Dementia in Intellectual Disability in Ireland. Aging \& Mental Health, 7, 413-417. https://doi.org/10.1080/13607860310001594655 